\title{
L-Tryptophan as Fluorescent Probe for Determination of Folic Acid in Some Pharmaceutical Products
}

\author{
Tara F. Tahir ${ }^{1}$, Aryan F. Qader ${ }^{2}$, Musher I. Salih $^{2}$, Essa Q. Rashid ${ }^{3}$ \\ ${ }^{1}$ Department of Medical Microbiology, Faculty of Science and Health, Koya University, \\ Koya KOY45, Kurdistan Region - F.R. Iraq \\ ${ }^{2}$ Department of Chemistry, Faculty of Science and Health, Koya University, \\ Koya KOY45, Kurdistan Region - F.R. Iraq \\ ${ }^{3}$ Kurdistan Medical Control Agency, Kurdistan Region - F.R. Iraq
}

\begin{abstract}
A new fluorescent probe L-Tryptophan was reported for the determination of folic acid (FA), based on its quenching effect of the fluorescence intensity of L-Tryptophan. The concentration of FA was proportional to the quenched fluorescence intensity of L-Tryptophan at excitation and emission wavelengths of $281 \mathrm{~nm}$ and $365 \mathrm{~nm}$, respectively, in Britton-Robinson buffer solution of pH 7. Optimized conditions of $\mathrm{pH}$, reaction time, potential interferences, concentrations of L-tryptophan, and buffer were investigated. FA was determined in a linear range of $2.0-16.0 \mu \mathrm{g} \mathrm{ml}$ with a correlation coefficient $R^{2} \mathbf{0 . 9 9 7 4}$. The limit of detection and limit of quantification values were $0.09 \mu \mathrm{g} / \mathrm{ml}$ and $0.27 \mu \mathrm{g} / \mathrm{ml}$, respectively. Relative standard deviation values for five replicated measurements of 2,8 , and $16 \mu \mathrm{g} / \mathrm{ml}$ FA were between $0.23 \%$ and $1.07 \%$. This method is efficient for routine analysis and quality control assay as it is relatively interferences free.
\end{abstract}

Index Terms-Folic acid, L-Tryptophan, Pharmaceutical tablet, Spectrofluorimetry.

\section{INTRODUCTION}

Vitamins are crucial for the growth and normal development of living beings. Vitamin $\mathrm{B}_{9}$ that belongs to water-soluble B-group vitamin is essential for human body and has different chemical forms, folic acid (FA) and folate (Nasser, et al., 2005; Catharino, et al., 2006; Zare, et al., 2011). Folate is the general formula of Vitamin $\mathrm{B}_{9}$ existed in food (Krishnaswamy and Nair, 2001) whereas FA is the synthetic form of this vitamin in the supplements and fortified foods (Bailey, 2000). FA has the chemical formula N-[4-[[(2-amino-3,4-dihydro4-oxo-6-pteridinyl)methyl]amino]benzoyl]-L-glutamic acid (Nagaraja, et al., 2002; Flores, et al., 2005; Deconinck, et al., 2011) (Fig. I). Human body is supplied with FA from its main dietary sources such as spinach, white beans, asparagus,

\footnotetext{
ARO-The Scientific Journal of Koya University Volume VII, No.2 (2019), Article ID: ARO.10557, 8 pages DOI: $10.14500 /$ aro. 10557

Received 04 August 2019; Accepted 07 October 2019

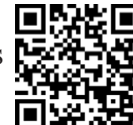

Regular research paper: Published 10 December 2019

Corresponding author's e-mail: tara.fuad@koyauniversity.org Copyright (C) 2019 Tara F. Tahir, Aryan F. Qader, Musher I. Salih,

Essa Q. Rashid. This is an open-access article distributed under the Creative Commons Attribution License.
}

dark-leaved vegetables, Brussels sprouts, soybean, oranges, and melons (Nasser, et al., 2005; Deconinck, et al., 2011). FA is vital for the formation and growth of red blood cells besides the prevention of anemia (Zhao, et al., 2006). This vitamin-like others cannot be synthesized by mammalian cells and must, therefore, be supplied in sufficient amounts in the diet (Aurora-Prado, et al., 2004).

Deficiency of Vitamin $B_{9}$ is resulted mainly from poverty, food preferences, drug use, and chronic alcoholism. In the case of the insufficient taking of Vitamin $\mathrm{B}_{9}$, multivitamin supplements can be used to prevent the associated physiological problems (Aurora-Prado, et al., 2004; Deconinck, et al., 2011). FA limitation can lead to congenital malformations in the fetus (spina bifida, encephalocele, cleft palate, and hydrocephalus), as well as heart disease (Czeize and Dudas, 1992; Crane, et al., 1995; Oakley, et al., 1995).

FA is important for normal growth, reproduction (during gestation and lactation), and antibody formation. It functions as a coenzyme in the metabolism of amino acids (glycine), the synthesis of purines, pyrimidines, DNA, and RNA is crucial for cell division and protein synthesis. Its defect can modify DNA synthesis and induce chromosomal changes (Pacheco, et al., 2009). Lack of FA causes high risk for neural tube defects (Pacheco, et al., 2009). The extremity of these defects means; it is important to undertake genetic counseling, supplement diets with FA, and perform prenatal diagnosis of neural tube defects (Pacheco, et al., 2009).

Although FA is nontoxic, there is some concern that high doses may mask pernicious anemia. This result is only likely following ingestion of quantities $>5 \mathrm{mg}$. Consuming medicines of FA levels above the approved value can be toxic to the patient (Kennedy, 2016). Therefore, there is a continuing necessity for the development of new analytical procedures for the determination of FA present in pharmaceutical formulations (Zhao, et al., 2006).

High-performance liquid chromatography (HPLC) is considered as a popular analytical technique for identification and quantification of FA in pharmaceutical formulations (PóoPrieto, et al., 2006). In spite of the advantages of HPLC as it is a well-established technology in the pharmaceutical field, offering sensitivity and specificity, it has disadvantages include 
high operating costs, the need for large amounts of samples and solvents, and the generation of hazardous wastes such as organic solvents that are expensive to dispose of and can have remarkable environmental impacts (Deconinck, et al., 2011).

In the literature the reported methods for the determination of FA include hyphenated techniques of HPLC with different detectors (Aurora-Prado, et al., 2004; Nelson, et al., 2006; Chaudhary, et al., 2010), electrophoresis (Zhao, et al., 2006), electrochemical methods (Vaze and Srivastava, 2007; Prasad, et al., 2010; Ensafi and Karimi-Maleh, 2010), flow injection analysis (Nie, et al., 2000), and spectrophotometric methods (Pesce and Bodourian, 1986; Rao, et al., 1978).

The use of derivative spectrophotometry provides a simple and inexpensive solution for the determination of drugs in pharmaceutical formulations. Meanwhile, using zero-order spectrophotometry for the determination of FA in complex samples that contain large amounts of interferents has the disadvantage of prior extraction of the analyte and thus increasing the costs of routine analysis (Moura and Moita, 2012).

Molecular fluorescence has one of the most attractive characteristics, its inherent sensitivity, which is often one to three orders of magnitude better than absorption spectroscopy. Actually, single molecules of selected species have been detected by fluorescence spectroscopy under controlled conditions. Besides, the large linear concentration ranges of fluorescence methods, which are remarkably broader than linear concentration range in absorption spectroscopy. However, the smaller number of chemical systems that show appreciable fluorescence has been made fluorescence methods less widely applicable than absorption methods (Cruces, et al., 1994; Skoog, et al., 2013). The aim of the present work was, therefore, to use a simple, low cost but sensitive and selective analytical method as spectrofluorimetry for quantification of FA in pharmaceuticals based on its quenching to the fluorescence emission of L-Tryptophan (Fig. II). The results were compared with the recommended method described in the literature.

\section{EXPERIMENTAL}

\section{A. Apparatus}

Fluorescence spectra measurements were carried out using Agilent Cary Eclipse Fluorescence Spectrophotometer, USA, with both slits width $5.0 \mathrm{~nm}$ and a quartz cell of $1.0 \mathrm{~cm}$ optimal path length. CyberScan $\mathrm{pH} 510 \mathrm{pH} / \mathrm{mV}$ meter was used for $\mathrm{pH}$ measurements of the solutions.

\section{B. Material and Reagent}

FA was obtained from Awamedica Pharmaceutical Company (Kurdistan Region-Iraq), used as received, the purity of which was $98 \%$. A solution of $4.0 \times 10^{-4} \mathrm{~mol} / \mathrm{L}$ L-Tryptophan (from Sigma-Aldrich) was prepared by dissolving $0.0082 \mathrm{~g}$ of the solid in $50.0 \mathrm{ml}$ of $0.1 \mathrm{~mol} / \mathrm{L}$ $\mathrm{NaOH}$ solution. Different buffer solutions were prepared by mixing proper volumes of $0.1 \mathrm{~mol} / \mathrm{L}$ sodium acetate (from Scharlau) and $0.1 \mathrm{~mol} / \mathrm{L}$ acetic acid (from Scharlau) to prepare acetate buffer solution; $0.1 \mathrm{~mol} / \mathrm{L} \mathrm{K}_{2} \mathrm{HPO}_{4}$ (from

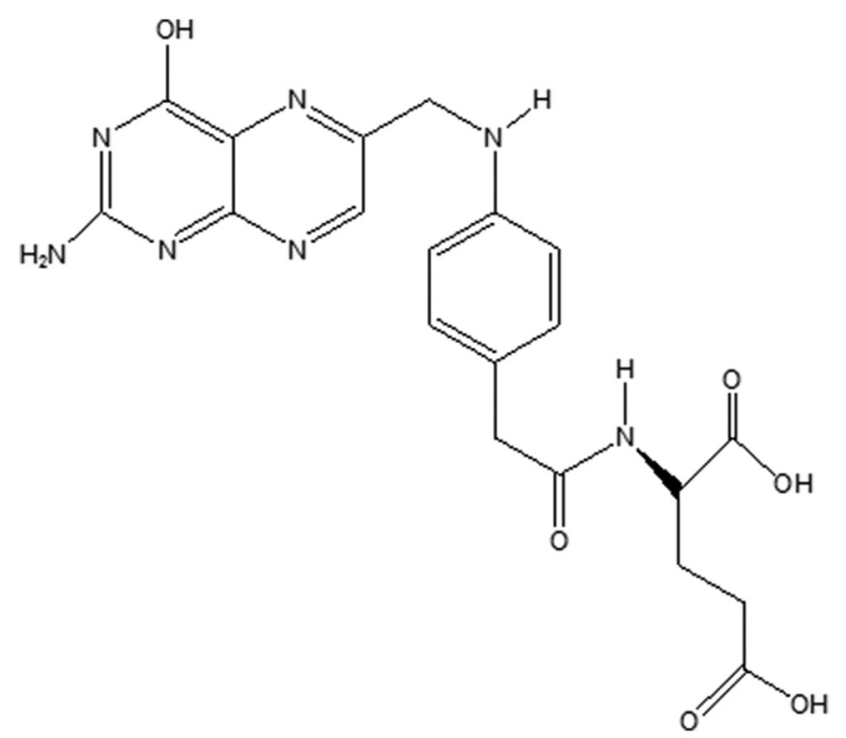

Fig. 1. Chemical structure of folic acid.

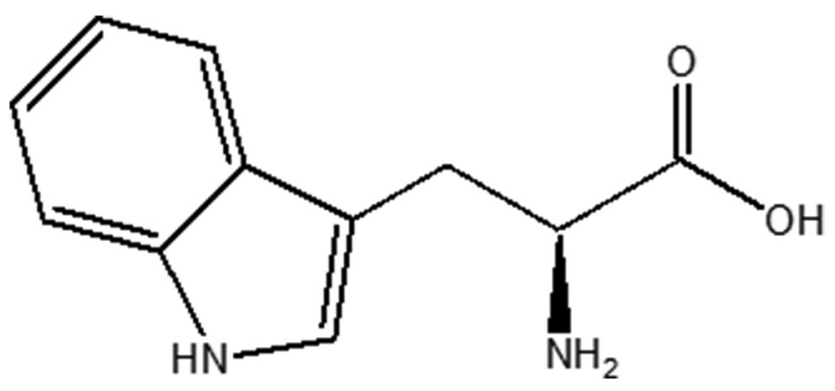

Fig. 2. Chemical structure of L-tryptophan.

Merck) and $0.1 \mathrm{~mol} / \mathrm{L} \quad \mathrm{KH}_{2} \mathrm{PO}_{4}$ (from Sigma-Aldrich) to prepare phosphate buffer solution; and $0.04 \mathrm{~mol} / \mathrm{L}$ phosphoric acid (from Merck), $0.04 \mathrm{~mol} / \mathrm{L}$ boric acid (from Sigma-Aldrich), and $0.04 \mathrm{~mol} / \mathrm{L}$ acetic acid (from Scharlau) to prepare Britton-Robinson (BR) buffer solution, respectively. A suitable volume of $0.2 \mathrm{~mol} / \mathrm{L}$ sodium hydroxide (from Merck) was then added to adjust the $\mathrm{pH}$ using a $\mathrm{pH}$ meter.

\section{Preparation of Standard and Sample Solution}

A stock solution of standard FA $(1.0 \mathrm{mg} / \mathrm{ml})$ was prepared by dissolving $0.05 \mathrm{~g}$ in $40.0 \mathrm{ml}$ of $0.1 \mathrm{~mol} / \mathrm{L} \mathrm{NaOH}$ with carefully stir, then completed to $50.0 \mathrm{ml}$ with the same solvent and kept in a cool dark place. Working standard solutions were prepared daily by proper dilution of the stock standard solution with the same solvent.

All pharmaceutical products of FA in the local medical store are containing $5 \mathrm{mg}$ and five different companies were used for the quantification; (Joriver, Jordan), (Wockhardt, UK), (Eipico, Egypt), (Actavis, US), and (Julphar, UAE). Ten tablets of FA were weighed and crushed for each pharmaceutical company, and then sample powder of the five companies was accurately weighed individually and placed in a $50.0 \mathrm{ml}$ beaker and dissolved with $40.0 \mathrm{ml}$ of $0.1 \mathrm{~mol} / \mathrm{L}$ $\mathrm{NaOH}$. The solution was stirred for $10 \mathrm{~min}$ to increase solubility. Insoluble excipient was removed by filtration using 
Whatman No.41 membrane filter paper. The filtered solution was diluted to $50.0 \mathrm{ml}$ with the same solvent.

\section{Analytical Procedure}

In $10.0 \mathrm{ml}$ volumetric flask, $0.25 \mathrm{ml}$ L-Tryptophan (4.0 $\left.\times 10^{-4} \mathrm{~mol} / \mathrm{L}\right), 0.8 \mathrm{ml} \mathrm{BR}$ buffer solution $(\mathrm{pH} \mathrm{7.0)}$, and adequate FA standard or sample $2.0-16.0 \mu \mathrm{g} / \mathrm{L}(0.2-1.6 \mathrm{ml})$ of $100 \mu \mathrm{g} / \mathrm{L}$ solution were added. This mixture was diluted to $10 \mathrm{ml}$ with distilled water and mixed thoroughly for $10 \mathrm{~min}$ at $25 \pm 2{ }^{\circ} \mathrm{C}$. The fluorescence intensity was measured against a blank with excitation wavelength at $281 \mathrm{~nm}$ and emission at $365 \mathrm{~nm}$.

\section{RESULTS AND DisCUSSION}

\section{A. Optimization of Experiment}

All parameters of the optimum conditions of fluorescence spectra of L-Tryptophan quenched by FA have been examined to obtain maximum sensitivity of the procedure. Different

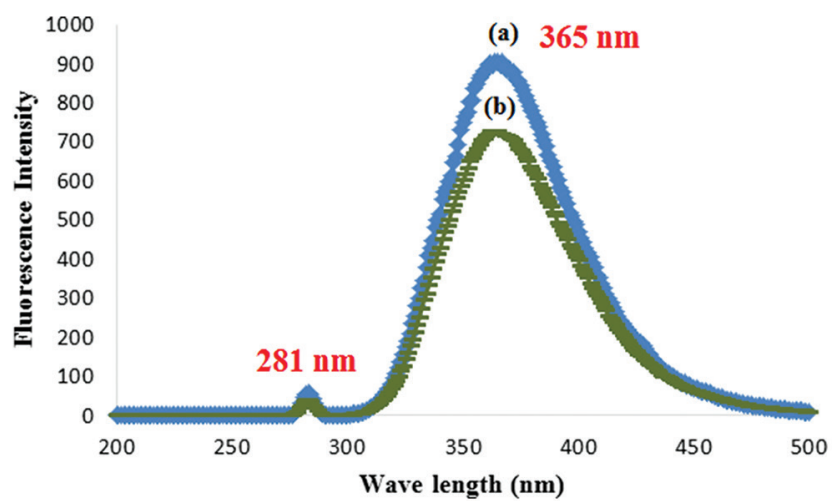

Fig. 3. Fluorescence excitation and emission spectra of (a) L-Tryptophan $\left(4.0 \times 10^{-4} \mathrm{~mol} / \mathrm{L}\right),(b)$ L-Tryptophan $\left(4.0 \times 10^{-4} \mathrm{~mol} / \mathrm{L}\right)$ with $5 \mu \mathrm{g} / \mathrm{ml}$ folic acid at $\mathrm{pH} 7$. parameters such as $\mathrm{pH}$, concentration of fluorescent probe L-Tryptophan, reaction time, and interferences were studied.

\section{Fluorescence emission spectra}

The fluorescence spectrum of L-Tryptophan $(4.0 \times$ $10^{-4} \mathrm{~mol} / \mathrm{L}$ ) solution was recorded at excitation and emission wavelengths at $281 \mathrm{~nm}$ and $365 \mathrm{~nm}$, respectively (Fig. IIIa). The intensity of the native fluorescence of L-Tryptophan marked quenches without any shift when $5 \mu \mathrm{g} / \mathrm{ml}$ FA was added to the solution containing $\left(4.0 \times 10^{-4} \mathrm{~mol} / \mathrm{L}\right)$ L-Tryptophan. A new ion associated complex, produced during quenching of L-Tryptophan fluorescence (Fig. IIIb). Therefore, L-Tryptophan could be used as a fluorescent probe for FA.

\section{pH buffer}

Different buffer solutions of $\mathrm{pH}$ range (2-10) were examined for the reaction of $4.0 \times 10^{-4} \mathrm{~mol} / \mathrm{L}$ L-Tryptophan solution with $5 \mu \mathrm{g} / \mathrm{ml} \mathrm{FA}$. Acetate buffer, phosphate buffer, and BR buffer were carried out in the reaction, individually (Fig. IVa). It was observed that BR buffer of $\mathrm{pH} 7$ has maximum intensity of quenched fluorescence spectrum of L-Tryptophan solution with FA due to the fact that FA acts as an acid and can quench the fluorescence spectrum of L-Tryptophan effectively in neutral medium. Therefore, this buffer was selected for next investigations.

To optimize the volume of BR buffer solution, different volumes $(0.2,0.4,0.6,0.8,1.0$, and $1.2 \mathrm{ml})$ were added to the solution of L-Tryptophan with FA where $0.8 \mathrm{ml}$ solution of BR buffer showed the maximum intensity of quenched fluorescence spectrum (Fig. IVb).

\section{L-Tryptophan concentration and reaction time}

Different volumes $(0.1-25 \mathrm{ml})$ of $4.0 \times 10^{-4} \mathrm{~mol} / \mathrm{L}$ L-Tryptophan reagent were investigated with fixed $(5 \mu \mathrm{g} / \mathrm{ml})$ concentration of FA and BR buffer solution ( $\mathrm{pH} 7)$ to obtain the maximum intensity of fluorescence spectrum. Fig. V showed that $0.25 \mathrm{~mL}$ volume of L-Tryptophan has maximum $\Delta \mathrm{F}$ intensity.
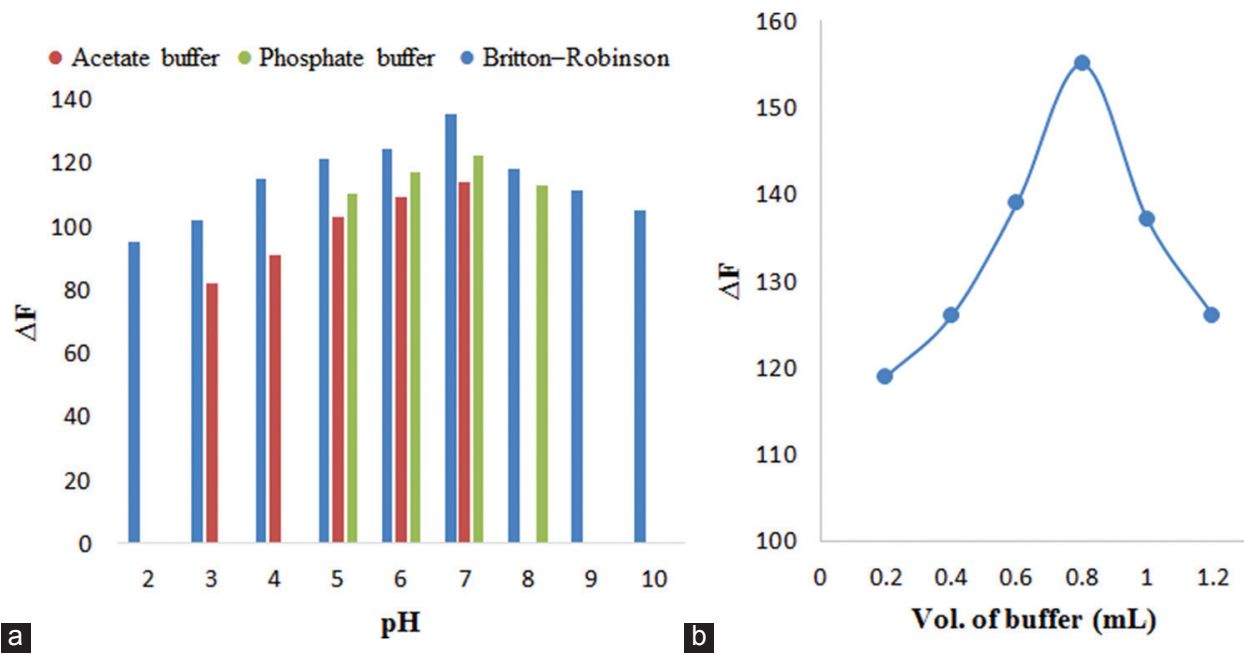

Fig. 4. (a) Effect of different $\mathrm{pH}$ buffer solutions on $\Delta \mathrm{F}$ intensity of $4.0 \times 10^{-4} \mathrm{~mol} / \mathrm{L}$ L-Tryptophan solution with $(5 \mu \mathrm{g} / \mathrm{ml})$ folic acid; (b) different volumes of Britton-Robinson buffer versus $\Delta \mathrm{F}$ intensity of L-Tryptophan solution with folic acid. 
The temperature had little influence on the fluorescence intensities of the system. The quenched fluorescence intensity $(\Delta \mathrm{F})$ slightly increased with temperature up to $20^{\circ} \mathrm{C}$ and then remained constant up to $25^{\circ} \mathrm{C}$. Therefore, room temperature $\left(25^{\circ} \mathrm{C}\right)$ was selected for further study. The reaction time of mixing L-Tryptophan with FA at ambient temperature $\left(25 \pm 2{ }^{\circ} \mathrm{C}\right)$ versus fluorescence intensity was also examined. It was found that quenching of the fluorescence intensity reached a maximum after $10 \mathrm{~min}$ from mixing the reagent with FA and remained constant for more than 100 min (Fig. VI).

\section{Evaluation of selectivity}

The excipients that are used in the pharmaceutical products in the form of tablets and capsules were used for selectivity assessment of FA under optimal experimental conditions (Manzoori, et al., 2011). The excipient solutions (500 $\mu \mathrm{g} \mathrm{ml})$ of lactose, fructose, glucose, starch, sucrose, and sodium chloride were mixed with $12 \mu \mathrm{g} / \mathrm{ml} \mathrm{FA}$ in $10 \mathrm{ml}$ of volumetric flask, individually. The spectra obtained were compared with the spectrum of $(12 \mu \mathrm{g} / \mathrm{ml})$ FA standard solution.

A level of interference was considered to be acceptable when the error is not higher than $3 \%$. No significant levels of interferences were observed in the determination of FA in the presence of the common excipients (Table I).

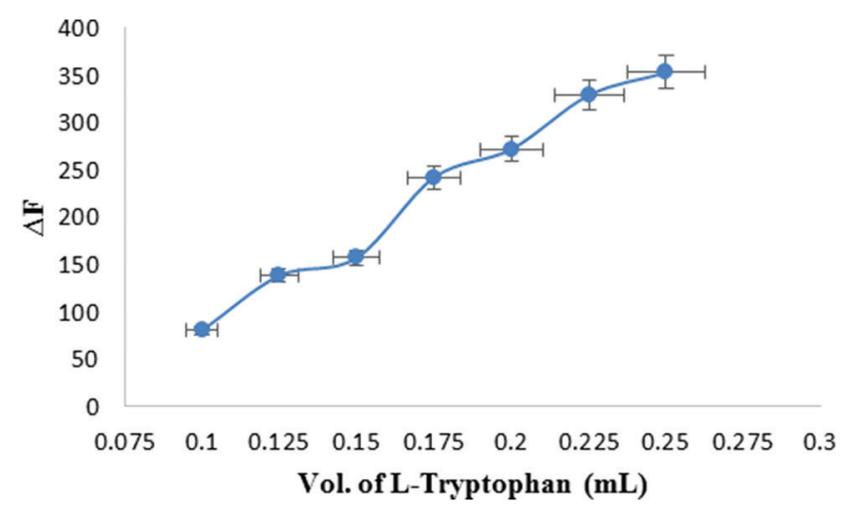

Fig. 5. Different volumes $(0.1-25 \mathrm{ml})$ of $4.0 \times 10^{-4} \mathrm{~mol} / \mathrm{L}$ L-Tryptophan and fixed $(5 \mu \mathrm{g} / \mathrm{ml})$ folic acid versus $\Delta \mathrm{F}$ intensity of the fluorescence.

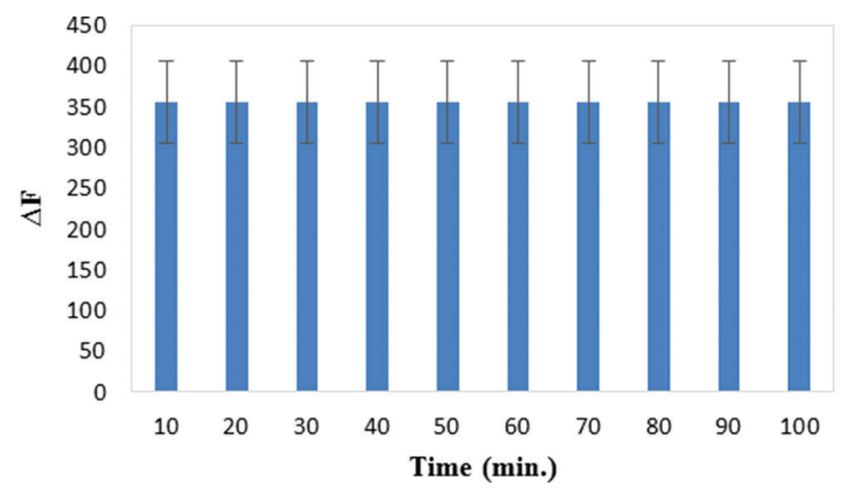

Fig. 6. Influence of reaction time of $4 \times 10^{-4} \mathrm{~mol} / \mathrm{L}$ L-Tryptophan with $(5$ $\mu \mathrm{g} / \mathrm{ml}$ ) folic acid at $\mathrm{pH} 7$ on $\Delta \mathrm{F}$ intensity of the fluorescence.

\section{B. Analytical Figures of Merit}

The determination of FA was investigated under optimum experimental conditions when the relative standard deviation (RSD\%) was $1.07 \%$ as obtained from five replicated measurements of three different concentrations of FA. According to IUPAC guidelines of the validation of analytical method, the limit of detection (LOD) value $=3.3$ $\mathrm{SD} / \mathrm{P}$ and limit of quantification (LOQ) on value $=10 \mathrm{SD} / \mathrm{P}$ were adopted, in which SD is the standard deviation of five reagent blank measurements and $\mathrm{P}$ is the gradient of the calibration curve (Abd Ali, et al., 2019). The linear range was 2-16 $\mu \mathrm{g} / \mathrm{ml}$ with correlation coefficient $\mathrm{R}^{2}=0.9974$ and LOD $0.09 \mu \mathrm{g} / \mathrm{ml}$ (Fig. VII). The regression equation of standard solutions was $\Delta \mathrm{F}=40.119 \mathrm{C}_{\mathrm{FA}}+140.2$ in which $\mathrm{C}_{\mathrm{FA}}$ is in $\mu \mathrm{g} / \mathrm{ml}$. The LOQ value of FA was $0.27 \mu \mathrm{g} / \mathrm{ml}$.

The accuracy and precision of the proposed procedure was established by measuring the fluorescence intensity of three concentrations of standard FA in five replicates measurements (Table II). The values of RSD $\%$ and $\mathrm{E} \%$ were between $1.10 \%-2.30 \%$ and $-2.50 \%-1.10 \%$, respectively, indicating that the method is valid and applicable.

\section{Stoichiometry of the Reaction}

The stoichiometry of the reaction between FA and L-Tryptophan was determined to adopt the limiting logarithmic method (Lakowicz, 2006). The proposed mechanism of the quenching reaction of FA and L-Tryptophan is the formation of an ion associated complex. Fig. VIII indicated a plot of $\log [\mathrm{FA}]$ versus $\log \Delta \mathrm{F}$ at constant concentration of L-Tryptophan and log [L-Tryptophan] versus $\log \Delta \mathrm{F}$ at constant concentration of $\mathrm{FA}$, respectively. Both plots were straight lines and depending on the gradients, the ratio of FA: L-Tryptophan complex is 1:1.

\section{Quenching Mechanism of L-Tryptophan and FA}

Fluorescence quenching is the decrease of the quantum yield of fluorescence from a fluorophore induced by a variety of molecular interactions, such as excited-state reactions, photoinduced electron transfer, fluorescence resonance energy transfer, ground-state complex formation, and collisional quenching (Bhattacharyya, et al., 1990). The physical origin of fluorescence quenching arising from the addition of a quenching agent, L-Tryptophan, to FA fluorescence can be

TABLE I

Evaluation of Selectivity of Fa Quantification Using L-Tryptophan Towards Some Common Excipients Presented in the Pharmaceutical PRODUCTS

\begin{tabular}{lcc}
\hline \hline Coexisting materials & Allowance concentrations $(\mu \mathrm{g} / \mathrm{ml})$ & $\mathrm{E} \%{ }^{*}$ \\
\hline Lactose & 500 & 2.10 \\
Fructose & 500 & 2.20 \\
Glucose & 500 & 1.80 \\
Starch & 500 & -1.40 \\
Sucrose & 500 & -2.10 \\
Sodium chloride & 500 & -1.50 \\
\hline \hline
\end{tabular}

*Average of three determinations 
interpreted in terms of the formation of ion-associated complex that enhanced fluorescence quenching. In this mechanism the fluorophore itself (FA) is fluorescent when the receptor site (amine group) is free. In the presence of L-Tryptophan, the fluorescence intensity is lowered due to the reaction between the carboxylic group of L-Tryptophan and receptor unit (amine group) of FA to form nonfluorescent ion-associated complex, and therefore, the net fluorescence is quenched. (Fig. IX).

Basically, this quenching process can be divided into two kinds of mechanisms: Static and dynamic quenching. Static and dynamic quenching can be distinguished by their different dependences on the temperature and excited-state lifetime. Dynamic quenching is diffusion controlled because the quencher (L-Tryptophan) must diffuse to the fluorophore

TABLE II

Precision And Accuracy Data of The Proposed Method

\begin{tabular}{lcccc}
\hline \hline $\begin{array}{l}\text { Contained amount } \\
(\mu \mathrm{g} / \mathrm{ml})\end{array}$ & $\begin{array}{c}\text { Found by proposed method } \\
(\mu \mathrm{g} / \mathrm{mL})\end{array}$ & SD & RSD\% & E\%* \\
\hline 2 & 1.95 & 2.30 & 1.07 & -2.50 \\
8 & 8.09 & 1.10 & 0.24 & 1.10 \\
16 & 16.08 & 1.80 & 0.23 & 0.50 \\
\hline \hline
\end{tabular}

*Average of five determinations

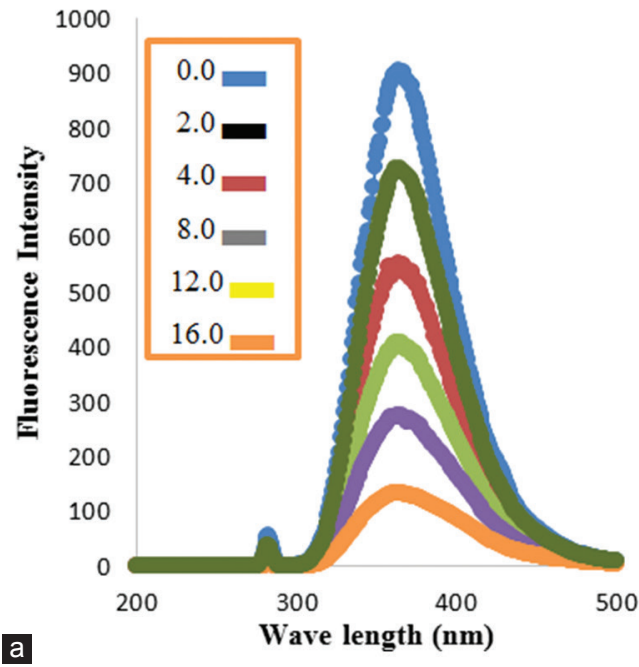

(FA) during the lifetime of the excited state. Since high temperature will result in a large diffusion coefficient, the bimolecular quenching constants are expected to increase with temperature. Static quenching implies either the existence of a sphere of effective quenching or the formation of a groundstate nonfluorescent complex, whereas collisional or dynamic quenching involves the collision followed by the formation of a transient complex between an excited-state fluorophore (FA) and a ground-state quencher (L-Tryptophan).

\section{E. Application to the Pharmaceutical Tablets}

The proposed procedure using L-Tryptophan as fluorescence probe for quantification of FA was applied to pharmaceutical tablets. The ingredients in the pharmaceutical tablets did not interfere in the quantification of FA. The applicability of the proposed procedure for the analysis of FA in pharmaceutical formulations was examined by investigating various pharmaceutical tablets, and the results are tabulated in Table III and were compared to the standard FA assay using HPLC method by means of t- and F-values at 95\% confidence level. HPLC has the ability to separate and identify compounds that are present in any sample that can be

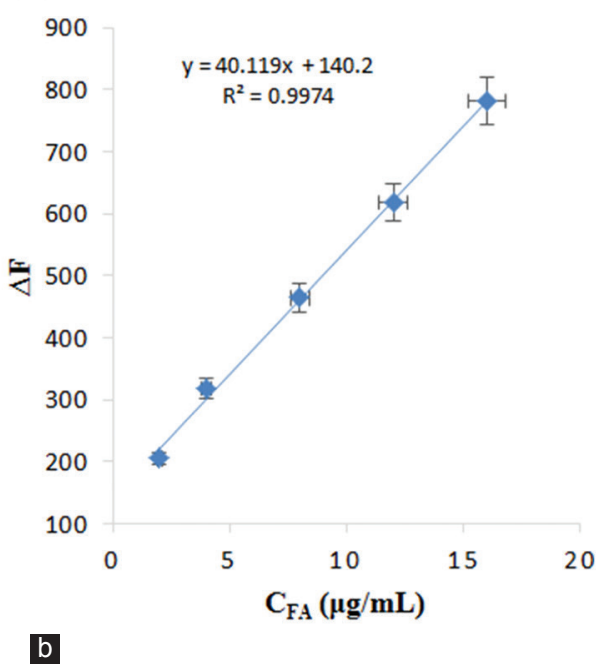

Fig. 7. (a) Different concentrations $(2,4,8,12$, and $16 \mu \mathrm{g} / \mathrm{ml})$ of folic acid versus fluorescence intensity of L-Tryptophan at $\mathrm{pH}$ 7. (b) Calibration curve of fluorometric quantitation of folic acid with L-Tryptophan under optimum condition.
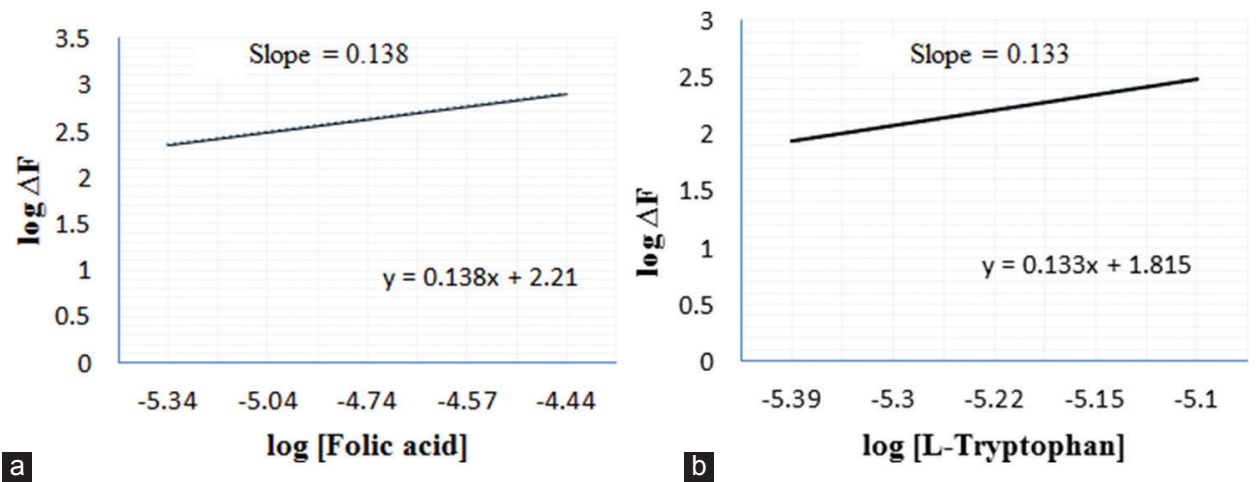

Fig. 8. Stoichiometric ratio of the fluorometric reaction of folic acid and L-Tryptophan reagent using a limiting logarithmic method. (a) Log[folic acid] versus $\log \Delta \mathrm{F}$ (b) Log [L-Tryptophan] versus $\log \Delta \mathrm{F}$. 


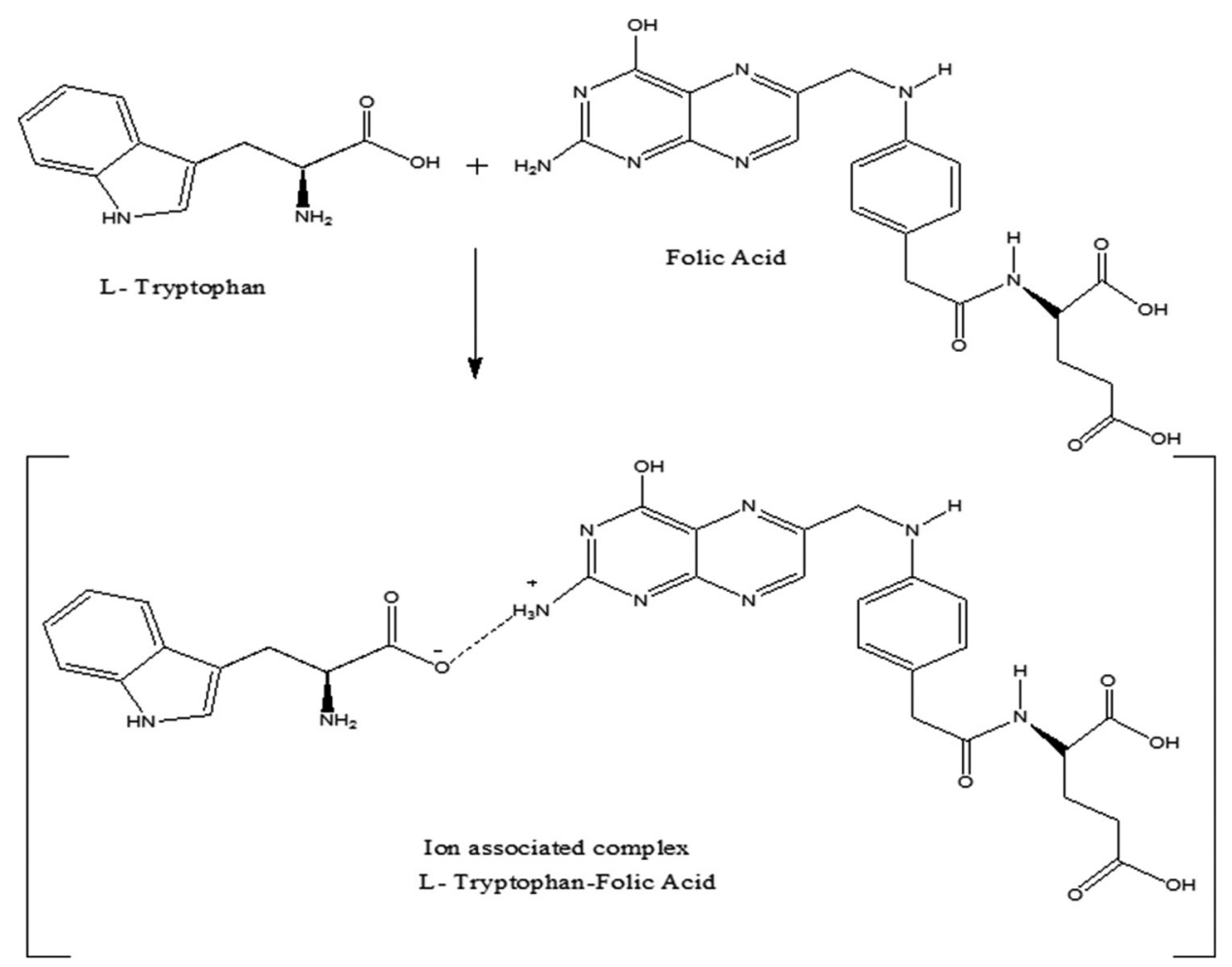

Fig. 9: Quenching mechanism of L-Tryptophan and folic acid due to the formation of ion associated complex.

TABLE III

Comparison of Fa Quantification in Pharmaceutical Tablets Using the Proposed Fluorometric L-Tryptophan Method and Standard Hplc Method

\begin{tabular}{|c|c|c|c|c|c|c|}
\hline Pharmaceutical Tablets & Observed values (mg) & Values from proposed procedure & Values from HPLC & Recovery \% & E \%* & $\mathrm{t}$ and $\mathrm{F}$ values** \\
\hline Joriver & 5 & $4.86 \pm 0.19$ & $4.98 \pm 0.02$ & 97.6 & -2.4 & $\mathrm{t}=0.40, \mathrm{~F}=1.50$ \\
\hline Wockhardt & 5 & $5.10 \pm 0.12$ & $5.01 \pm 0.10$ & 101.8 & 1.8 & $\mathrm{t}=1.95, \mathrm{~F}=1.00$ \\
\hline Eipico & 5 & $5.14 \pm 0.20$ & $5.21 \pm 0.05$ & 98.7 & -1.3 & $\mathrm{t}=0.73, \mathrm{~F}=2.20$ \\
\hline Julphar & 5 & $4.79 \pm 0.13$ & $4.88 \pm 0.01$ & 98.2 & -1.8 & $\mathrm{t}=0.23, \mathrm{~F}=3.20$ \\
\hline
\end{tabular}

*Average of five determinations. ${ }^{* *}$ Theoretical calculation of $\mathrm{t}$ and $\mathrm{F}$ at $95 \%$ confidence level $(n=5)$ were 2.78 and 6.39 respectively

TABLE IV

Comparison of Determination of Folic Acid Using Different Analytical Techniques and the Proposed Method

\begin{tabular}{|c|c|c|c|c|c|}
\hline Method's name & Ref. & LR & LOD & LOQ & $\mathrm{pH}$ \\
\hline Spectrophotometer & Al-Araji, et al., 2017 & $0.75-10.50 \mu \mathrm{g} / \mathrm{mL}$ & $0.159 \mu \mathrm{g} / \mathrm{mL}$ & $0.531 \mu \mathrm{g} / \mathrm{mL}$ & 11.0 \\
\hline Spectrofluorimeter & Manzoori, et al., 2011 & $0.01-1.10 \mathrm{mg} / \mathrm{L}$ & $0.003 \mathrm{mg} / \mathrm{L}$ & - & 6.2 \\
\hline Chromatography & Nelson, et al., 2006 & $0.02-73 \mathrm{ng}$ & $0.02 \mathrm{ng}$ & $0.06 \mathrm{ng}$ & 6.0 \\
\hline HPLC & El-Leithy, et al., 2018 & $0.1-2 \mu \mathrm{g} / \mathrm{mL}$ & $0.1 \mu \mathrm{g} / \mathrm{mL}$ & - & $3.5-7.4$ \\
\hline Proposed method & - & $2.0-16.0 \mu \mathrm{g} / \mathrm{mL}$ & $0.09 \mu \mathrm{g} / \mathrm{mL}$ & $0.27 \mu \mathrm{g} / \mathrm{ml}$ & 7.0 \\
\hline
\end{tabular}

HPLC: High-performance liquid chromatography, LOD: Limit of detection, LOQ: Limit of quantification

dissolved in a liquid in trace concentrations as low as parts per trillion. The sample mixture or analyte is pumped with a solvent (mobile phase) in a column with chromatographic packing material (stationary phase) at high pressure. The sample is carried by a moving carrier gas stream of helium or nitrogen. Sample retention time will vary depending on the interaction between the stationary phase, the molecules being analyzed, and the solvent used. As the sample passes through the column it interacts between the two phases at different rates, primarily due to different polarities of analytes in the sample. Analytes that have the least amount of interaction with the stationary phase or the most amount of interaction with the mobile phase will exit the column faster. The HPLC system of Agilent 1100 controlled by ChemStation Data41 System and equipped with G 1311A quaternary pump and UV detector (VWD-G1314 A) was employed for the investigation. A reverse phase C18 column (Kromasil 100-5 Phenyl $\left.{ }^{\circledR}, 300 \mathrm{~mm} \times 4.6 \mathrm{~mm}, 5 \mu \mathrm{m}\right)$ was used at $25^{\circ} \mathrm{C}$. The experiment was run with mobile phase consisted of $0.1 \% \mathrm{v} / \mathrm{v}$ trifluoroacetic acid (TFA) and acetonitrile at ratio $(80: 20 \mathrm{v} / \mathrm{v})$. It was injected with flow rate $1.5 \mathrm{ml} / \mathrm{min}$, and the elute was monitored at wavelength $290 \mathrm{~nm}$. 
In all cases, the average results obtained by the proposed procedure and standard method were statistically identical, and there were no significant differences between them at 95\% confidence level. Therefore, the proposed methods are simple, sensitive, and reproducible and can be used for routine analysis of FA in pharmaceutical formulations.

Table IV shows the optimization results of the determination of FA using different analytical techniques and the proposed method. Although some analytical techniques have lower LOD value and wider linear range, the proposed method does not need pre-extraction of the sample besides the low cost of the technique compared with others such as HPLC.

\section{CONCLUSION}

The proposed spectrofluorometry is simple, rapid, inexpensive, sensitive, and reproducible method for routine analysis of FA in pharmaceutical formulations without interference from common tablet excipients. The method has wide linear range with good accuracy and precision. The significance of the proposed method is direct measurement of FA in pharmaceutical formulations without need for pretreatment of the drug and extraction with organic solvent. Therefore, the method can be used successfully for quality control of FA in its dosage forms.

\section{REFERENCES}

Abd Ali, L.I., Qader, A.F., Salih, M.I., and Aboul-Enein, H.Y., 2019. Sensitive spectrofluorometric method for the determination of ascorbic acid in pharmaceutical nutritional supplements using acriflavine as a fluorescence reagent. Luminescence, 34(2), pp.168-174.

Al-Araji, R.R., Mashkour, M.S., and Jaffar Al-Mulla, E.A., 2017. Spectrophotometric determination of vitamin folic acid B9 in some drugs using 1, 2-naphthoquine-4-sulphonate (NQS). Nano Biomedicine and Engineering, 9(3), pp.208-213.

Aurora-Prado, M.S., Silva, C.A., Tavares, M.F., and Altria, K.D., 2004. Determination of folic acid in tablets by microemulsion electrokinetic chromatography. Journal of Chromatography A, 1051(1), pp.291-296.

Bailey, L.B., 2000. New standard for dietary folate intake in pregnant women. The American Journal of Clinical Nutrition, 71(5), pp.1304-1307.

Bhattacharyya, M., Chaudhuri, U., Poddar, R.K., 1990. Evidence for cooperative binding of CPZ with hemoglobin. Biochemical and Biophysical Research Communications, 167, pp.1146-1153.

Catharino, R.R., Godoy, H.T., and Lima-Pallone, J.A., 2006. Analytical methodology for folate and folic acid determination in food. Quimica Nova, 29(5), pp.970-972.

Chaudhary, A., Wang, J., and Prabhu, S., 2010. Development and validation of a high-performance liquid chromatography method for the simultaneous determination of aspirin and folic acid from nano-particulate systems. Biomedical Chromatography, 24(9), pp.919-925.

Crane, N.T., Wilson, D.B., Cook, D.A., Lewis, C.J., Yetley, E.A., and Rader, J.I., 1995. Evaluating food fortification options: General principles revisited with folic acid. American Journal of Public Health, 85(5), pp.660-666.

Cruces, B.C., Segura, C.A., Fernández, G.A., and Román, C.M., 1994. Fluorometric determination of folic acid based on its reaction with the fluorogenic reagent fluorescamine. Analytical Letters, 27(7), pp.1339-1353.
Czeize, A.E., and Dudas, I., 1992. Prevention of the first occurrence of neural tube defects by perioconceptional vitamin supplementation. The New England Journal of Medicine, 327(226), pp.1832-1835.

Deconinck, E., Crevits, S., Baten, P., Courselle, P., and De Beer, J., 2011. A validated ultra-high pressure liquid chromatographic method for qualification and quantification of folic acid in pharmaceutical preparations. Journal of Pharmaceutical and Biomedical Analysis, 54(5), pp.995-1000.

El-Leithy, E.S., Abdel-Bar, H.M., and El-Moneum, R.A., 2018. Validation of high performance liquid chromatographic method for folic acid assay. International Journal of Pharmaceutical Science Invention, 7(1), pp.1-5.

Ensafi, A.A., and Karimi, M.H., 2010. Modified multiwall carbon nanotubes paste electrode as a sensor for simultaneous determination of 6-thioguanine and folic acid using ferrocenedicarboxylic acid as a mediator. Journal of Electroanalytical Chemistry, 640(1), pp.75-83.

Flores, J.R., Penalvo, G.C., Mansilla, A.E., and Gomez, M.J., 2005. Capillary electrophoretic determination of methotrexate, leucovorin and folic acid in human urine. Journal of Chromatography B, 819(1), pp.141-147.

Kennedy, D., 2016. B vitamins and the brain: Mechanisms, dose and efficacy a review. Nutrients, 8(2), p.68.

Krishnaswamy, K., and Nair, K.M., 2001. Importance of folate in human nutrition. British Journal of Nutrition, 85(2), pp.115-124.

Lakowicz, J.R., 2006. Principles of Fluorescence Spectroscopy. $3^{\text {rd }}$ ed. New York: Springer. pp.277-330.

Manzoori, J.L., Jouyban, A., Amjadi, M., and Soleymani, J., 2011. Spectrofluorimetric determination of folic acid in tablets and urine samples using 1, 10-phenanthroline-terbium probe. Luminescence, 26, pp.106-111.

Mirmoghtadaie, L., Ensafi, A.A., Kadivar, M., Shahedi, M., and Ganjali, M.R., 2013. Highly selective, sensitive and fast determination of folic acid in food samples using new electrodeposited gold nanoparticles by differential pulse voltammetry. International Journal of Electrochemical Science, 8, pp.3755-3767.

Moura, J.I., and Moita, G.C., 2012. Simultaneous determination of olanzapine and fluoxetine hydrochloride in pharmaceutical formulations by derivative spectrophotometry. Química Nova, 35(3), pp.627-633.

Nagaraja, P., Vasantha, R.A., and Yathirajan, H.S., 2002. Spectrophotometric determination of folic acid in pharmaceutical preparations by coupling reactions with iminodibenzyl or 3-aminophenol or sodium molybdate pyrocatechol. Analytical Biochemistry, 307(2), pp.316-321.

Nasser, C., Nobre, C., Mesquita, S., Ruiz, J.G., Carlos, H.R., Prouvot, L., and Yacubian, M.T., 2005. Natural variation of folate in cowpea seeds. Journal of Epilepsy and Clinical Neurophysiology, 11(4), pp.199-203.

Nelson, B.C., Sharpless, K.E., and Sander, L.C., 2006. Quantitative determination of folic acid in multivitamin/multielement tablets using liquid chromatography/ tandem mass spectrometry. Journal of Chromatography A, 1135(2), pp.203-211.

Nie, F., He, Y., and LU, J., 2000. An investigation of the chemiluminescence reaction in the sodium hypochlorite-folic acid-semicarbazide hydrochloride system. Microchemical Journal, 65(3), pp.319-323.

Oakley, G.P., Erickson, J.D., and Adams, M.J., 1995. Urgent need to increase folic acid consumption. JAMA, 274(21), pp.1717-1718.

Pacheco, S.S., Braga, C., Souza, A.I.D., and Figueiro, J.N., 2009. Effects of folic acid fortification on the prevalence of neural tube defects. Revista de Saúde Pública, 43(4), pp.565-571.

Pesce, M.A., and Bodourian, S.H., 1986. Evaluation of a fluorescence polarization immunoassay procedure for quantitation of methotrexate. Therapeutic Drug Monitoring, 8(1), p.115.

Póo-Prieto, R., Haytowitz, D.B., Holden, J.M., Rogers, G., Choumenkovitch, S.F., Jacques, P.F., and Selhub, J., 2006. Use of the affinity/HPLC method for quantitative estimation of folic acid in enriched cereal-grain products. The Journal of Nutrition, 136(12), pp.3079-3083. 
Prasad, B.B., Tiwari, M.P., Madhuri, R., and Sharma, P.S., 2010. Development of a highly sensitive and selective hyphenated technique (molecularly imprinted micro-solid phase extraction fiber-molecularly imprinted polymer fiber sensor) for ultratrace analysis of folic acid. Analytica Chimica Acta, 662(1), pp.14-22.

Rao, G.R., Kanjilal, G., and Mohan, K.R., 1978. Extended application of folinciocalteu reagent in the determination of drugs. Analyst, 103(1230), pp.993-994.

Skoog, D.A., West, D.M., Holler, F.J., and Crouch, S.R., 2013. Fundamentals of Analytical Chemistry. $9^{\text {th }}$ ed. Cengage Learning, Boston.

Vaze, V.D., and Srivastava, A.K., 2007. Electrochemical behavior of folic acid at calixarene based chemically modified electrodes and its determination by adsorptive stripping voltammetry. Electrochimica Acta, 53(4), pp.1713-1721.

Zare, H.R., Shishehbore, M.R., and Nematollahi, D., 2011. A highly sensitive and selective sensor on the basis of 4-hydroxy-2-(triphenylphosphonio) phenolate and multi-wall carbon nanotubes for electrocatalytic determination of folic acid in presence of ascorbic acid and uric acid. Electrochimica Acta, 58, pp.654-661.

Zhao, S., Yuan, H., Xie, C., and Xiao, D., 2006. Determination of folic acid by capillary electrophoresis with chemiluminescence detection. Journal of Chromatography A, 1107(1), pp. 290-293. 